\title{
Heat Transfer via Unconditioned Spaces: The Influence of the Adjustment Factor Evaluation Method
}

\author{
Stefano Bergero, Anna Chiari* \\ DAD - Department of Architecture and Design, Polytechnic School, University of Genova, Stradone S. Agostino 37, Genova \\ 16123 , Italy
}

Corresponding Author Email: anna.chiari@unige.it

https://doi.org/10.18280/ti-ijes.632-439

Received: 6 March 2019

Accepted: 4 May 2019

\section{Keywords:}

unconditioned spaces, adjustment factor $b_{t r, U}$, thermal bridges, building energy need, UNI/TS 11300-1 calculation procedure

\begin{abstract}
The aim of the paper is to determine the influence of the evaluation method of the heat transfer via unconditioned spaces in building energy need calculation procedure, taking into account the dispositions of the UNI/TS 11300-1 standard.

Two different calculation methods for the adjustment factor btr, $\mathrm{U}$ are compared with reference to a case study of a '70 years condominium building: the simplified method, based on the tabulated values, available only for existing buildings, and the detailed one, based on the analytical calculation of the heat transfer coefficient Hue between unconditioned spaces and external environment, available for both new and existing buildings. In the latter case, the influence of thermal bridges between unconditioned rooms (cellars, attics, stairwells) and the outside and the ground is also considered.

Results are discussed in terms of both btr, $\mathrm{U}$ factor and temperature $\mathrm{Tu}$ of the unconditioned spaces. The energy need of single apartments has also been calculated in order to evaluate the influence of the calculation procedure on heating millesimal table of the condominium. Results of simulations reveal significant differences on single units energy needs between the detailed and simplified method; the contribution of thermal bridges in Hue coefficient calculation is negligible.
\end{abstract}

\section{INTRODUCTION}

UNI/TS 11300-1 standard [1], which is the Italian transposition of the international standard UNI EN ISO 13790 [2], provides two methods in order to determine the adjustment factor $b_{t r, U}$ for thermally unconditioned spaces. The simplified method is based on the tabulated values, available only for existing buildings; the detailed one is based on the analytical calculation of the heat transfer coefficient $\mathrm{H}_{\mathrm{ue}}$ between unconditioned spaces and external environment, available for both new and existing buildings when all construction details are known. This approach has been substantially maintained by the UNI EN ISO 52016-1 [3] standard, which has recently cancelled and replaced the UNI EN ISO 13790 and introduced the dynamic hourly calculation method in the evaluation of the energy performance of buildings.

A '70 years condominium residential building, consisting of three blocks each of five floors for a total of 30 housing units, cellars, attics and stairwells unheated, has been considered as case study. The details of opaque and glazed building elements and thermal bridges have been obtained from inspections and design documents.

With reference to the same case study, in a previous paper [4] a discussion concerning the calculation method of linear thermal transmittance $\psi$ of thermal bridges that compete to the conditioned spaces was carried out. The goal of the present paper is to determine the influence of the heat transfer via unconditioned spaces evaluation method in building energy need calculation procedure.

Three different calculation procedures for the heat transfer via thermally unconditioned spaces are compared:

(1). default values of the $b_{t r, U}$ factor, with reference to Table 7 of the UNI/TS 11300-1 standard;

(2). detailed calculation of the $b_{t r, U}$ factor by the formula 29 of the UNI/TS 11300-1 standard, neglecting the influence of thermal bridges in $\mathrm{H}_{\mathrm{ue}}$ coefficient calculation;

(3). detailed calculation of the $b_{t r, U}$ factor by the formula 29 of the UNI/TS 11300-1 standard, considering the influence of thermal bridges in $\mathrm{H}_{\mathrm{ue}}$ coefficient calculation.

(4). In the last case, all linear transmittances of thermal bridges between unconditioned spaces and external environment are numerically calculated by THERM software [5]; for cellars, via ground linear thermal bridges are also considered.

In all cases, linear transmittances of thermal bridges concerning conditioned rooms are numerically calculated by THERM software, as described in [4].

The three above mentioned procedures present increasing difficulties and execution times; in particular, the calculation of thermal bridges for the $\mathrm{H}_{\mathrm{ue}}$ coefficient determination is laborious, and it is often overlooked by the technicians who compile the diagnosis and the energy certification of buildings.

Comparison between the different calculation procedures has been obtained with reference to both the needs of the entire building and to that of each housing unit, distinguishing between the apartments located on the first and the last floors and those located on the intermediate floors. Condominium heating millesimal tables, according to the Italian UNI 10200 standard [6], are also compiled in order to divide the cost of involuntary consumption (due to plant generation and 
distribution energy losses and to the plant management and maintenance) between the various real estate units in the case of a building equipped with centralized heating system and with thermal control and heat metering devices.

\section{CALCULATION PROCEDURE}

The transmission heat transfer coefficient $\mathrm{H}_{U}$ between a conditioned zone and the external environments via a thermally unconditioned space is obtained as:

$\mathrm{H}_{\mathrm{U}}=\mathrm{H}_{\mathrm{tr}, \mathrm{iu}} \mathrm{b}_{\mathrm{tr}, \mathrm{U}}$

$\mathrm{H}_{\mathrm{tr}, \text { iu }}=$ transmission heat transfer coefficient between the conditioned and unconditioned spaces

$b_{t r, U}=$ adjustment factor of the heat transfer between the conditioned and unconditioned spaces with value $b_{t r, U} \neq 1$ if the temperature of the unconditioned room is not equal to the temperature of the external environment

The UNI/TS 11300-1 standard provides two methods in order to determine $b_{t r, U}$ factor, that adjusts the heat transfer coefficient $\mathrm{H}_{\mathrm{U}}$ instead of the temperature difference.

The simplified method, available for existing building in absence of design values and reliable input data, consists in assuming a default value of the $b_{t r, U}$ factor depending on the type and/or size of the unconditioned space, based on Table 7 of the standard itself, derived from the UNI EN 12831-1 [7]. This value includes the effect of the internal and solar gains and the extra heat flux due to thermal radiation to the sky. This is equivalent to setting the monthly temperature of the unconditioned space $T_{u}$, which is determined by the following relation:

$\mathrm{T}_{\mathrm{u}}=\mathrm{T}_{\mathrm{i}}-\mathrm{b}_{\mathrm{tr}, \mathrm{U}}\left(\mathrm{T}_{\mathrm{i}}-\mathrm{T}_{\mathrm{e}}\right)$

$\mathrm{T}_{\mathrm{i}}=$ internal set point temperature of the building

$\mathrm{T}_{\mathrm{e}}=$ external monthly temperature

The detailed method, available for both new and existing buildings, provides the following relation for the adjustment factor $b_{\mathrm{tr}, \mathrm{U}}$ :

$\mathrm{b}_{\mathrm{tr}, \mathrm{U}}=\frac{\mathrm{H}_{\mathrm{ue}}}{\mathrm{H}_{\mathrm{iu}}+\mathrm{H}_{\mathrm{ue}}}$

$\mathrm{H}_{\mathrm{iu}}=$ heat transfer coefficient between conditioned and unconditioned spaces

$\mathrm{H}_{\mathrm{ue}}=$ heat transfer coefficient between unconditioned space and external environment, including heat transfer via ground

Both $\mathrm{H}_{\mathrm{iu}}$ and $\mathrm{H}_{\mathrm{ue}}$ coefficients must be determined according to UNI EN ISO 13789 [8], including the transmission $\mathrm{H}_{\text {tr }}$ and ventilation $\mathrm{H}_{\mathrm{ve}}$ heat transfer coefficients:

$\mathrm{H}=\mathrm{H}_{\mathrm{ve}}+\mathrm{H}_{\mathrm{tr}}$

Transmission coefficients $\mathrm{H}_{\mathrm{tr}}$ ue and $\mathrm{H}_{\mathrm{tr}, \text { iu }}$ are evaluated by the following relation:

$\mathrm{H}_{\mathrm{tr}}=\sum_{\mathrm{i}} \mathrm{A}_{\mathrm{i}} \mathrm{U}_{\mathrm{i}}+\sum_{\mathrm{k}} \mathrm{L}_{\mathrm{k}} \Psi_{\mathrm{k}}$

$\mathrm{U}_{\mathrm{i}}=$ thermal transmittance of the opaque or glazed $\mathrm{i}^{\text {th }}$ element of area $A_{i}$ $\psi_{\mathrm{k}}=$ linear thermal transmittance of the $\mathrm{k}^{\text {th }}$ thermal bridge of length $\mathrm{L}_{k}$

Only ventilation coefficient between unconditioned space and external environment has to be determinate, being the air flow rate between conditioned and unconditioned spaces equal to zero according to UNI EN ISO 13789:

$\mathrm{H}_{\mathrm{ve}, \mathrm{ue}}=\rho_{\mathrm{a}} \mathrm{c}_{\mathrm{a}} \mathrm{V}_{\mathrm{u}} \mathrm{n}_{\mathrm{ue}} / 3600$

$\rho_{\mathrm{a}}=1.2 \mathrm{~kg} \mathrm{~m}^{-3}$, air density

$\mathrm{c}_{\mathrm{a}}=1.0 \mathrm{~kJ} \mathrm{~kg}^{-1} \mathrm{~K}^{-1}$, air constant pressure specific heat

$\mathrm{V}_{\mathrm{u}}=$ net volume of unconditioned space

$\mathrm{n}_{\mathrm{ue}}=$ hourly air change rate between unconditioned space and the external environment, based on Table 2 of the UNI EN ISO 13789 and assumed equal to $0.5 \mathrm{~h}^{-1}$ for all unconditioned spaces (all joints between components well sealed, no permanent ventilation openings)

The $b_{t r, U}$ factor calculated according to equation (3) doesn't take into account the internal and solar gains and the extra heat flux to the sky of the unconditioned space; it follows that the temperature of the unconditioned space is:

$\mathrm{T}_{\mathrm{u}}=\frac{\Phi+\mathrm{T}_{\mathrm{i}} \mathrm{H}_{\mathrm{iu}}+\mathrm{T}_{\mathrm{e}} \mathrm{H}_{\mathrm{ue}}}{\mathrm{H}_{\mathrm{iu}}+\mathrm{H}_{\mathrm{ue}}}=\frac{\Phi \mathrm{b}_{\mathrm{tr}, \mathrm{U}}}{\mathrm{H}_{\mathrm{ue}}}+\mathrm{T}_{\mathrm{i}}\left(1-\mathrm{b}_{\mathrm{tr}, \mathrm{U}}\right)+\mathrm{T}_{\mathrm{e}} \mathrm{b}_{\mathrm{tr}, \mathrm{U}}$

$\Phi=$ heat flux generated in the unconditioned space, including extra heat flux due to thermal radiation to the sky from the unconditioned environment and internal and solar heat gains in the unconditioned space through opaque and glazed envelope.

When calculating the temperature of an unconditioned space, heat transfer with other neighboring unconditioned environments characterized by different values of the $b_{t r, U}$ coefficient is neglected in accordance with Annex A of the UNI/TS 11300-1.

Internal gains in unconditioned spaces are also neglected, not being significant, in accordance with par. 13.1.3 of UNI/TS 11300-1.

\section{CASE STUDY}

A cooperative residential building, built in 1973, located in the outskirts of Novi Ligure (AL) and consisting of 3 distinct blocks each on 5 levels for a total of 30 apartments, has been considered.

Novi Ligure is located in E climatic zone of the Italian territory; the conventional heating season runs from October 15th to April 15th for a total of 183 heating days.

The main features of the building are described in [4]. In the present paper, only information concerning unconditioned spaces has been added. The unconditioned spaces of the building are the cellars on the ground floor, the stairwells and the attics under the pitched roof, as shown in Figure 1. In the table attached to Figure 1 the volume, the useful surface and the btr, $\mathrm{U}$ factor assumed in the case of simplified calculation

procedure in accordance with Table 7 of UNI/TS 11300-1 are reported for each unconditioned room. In particular:

The six cellars have external windows, $b t r, U=0.8$;

The three stairwells have doors and windows and at least two external walls (the roof and the vertical wall),

btr, $\mathrm{U}=0.6$; 
The building roof is not insulated and six attics are well sealed, btr, $\mathrm{U}=0.9$.

Heat exchange area and corresponding thermal transmittance of different elements of the unconditioned spaces are shown in Table 1, for both walls and windows. It should be noted the reduced usable area of the cellars on the ground floor because a significant portion of the floor of the first floor faces outwards on a portico [4].

Thermal transmittances are also represented by the thermographic picture in Figure 1. In particular, it can be noted the blue adiabatic wall between two different unconditioned rooms.

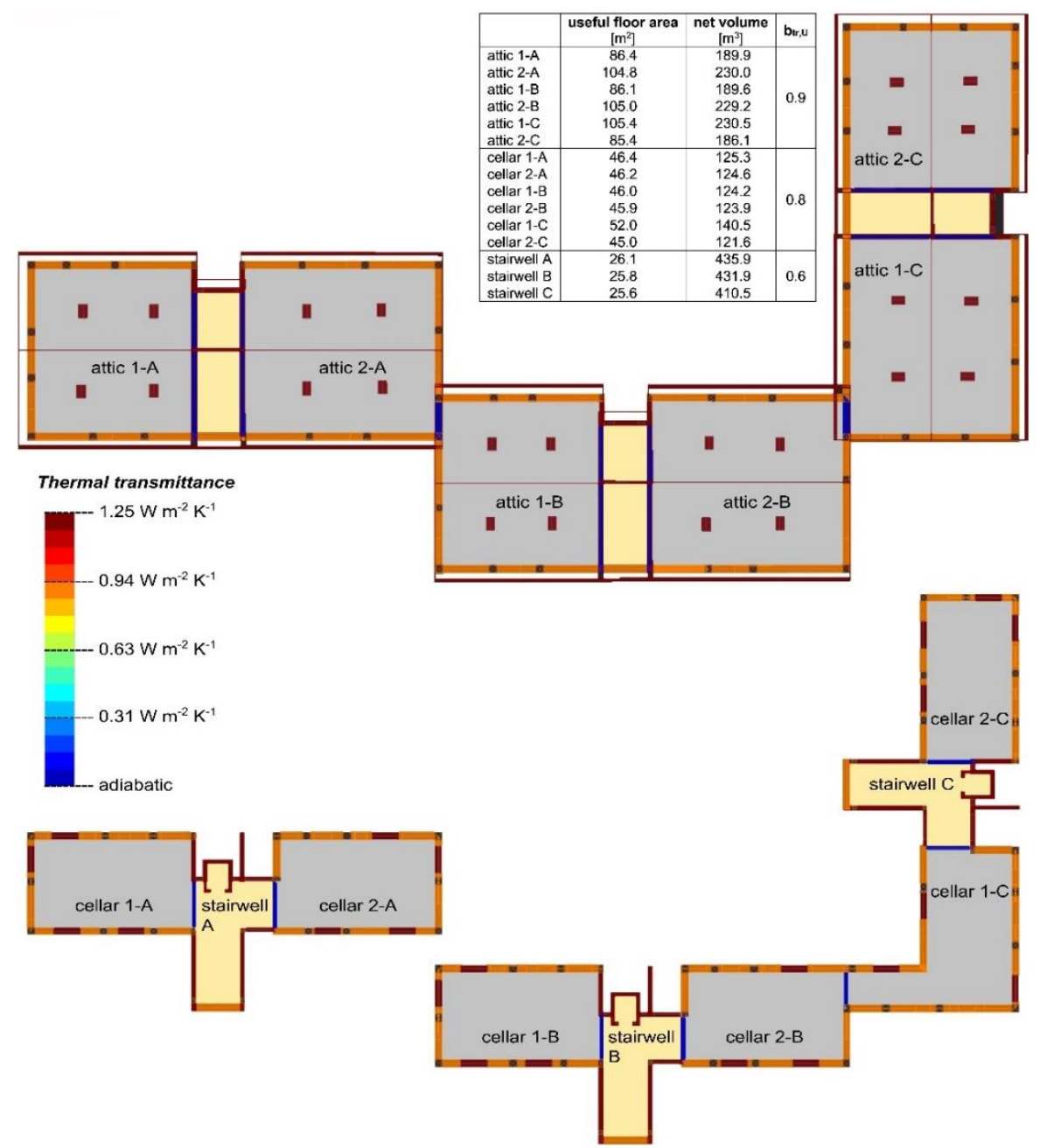

Figure 1. Plan of the building at the level of attics and cellars

Table 1. Heat exchange area and thermal transmittance of building elements of the unconditioned spaces

\begin{tabular}{ccc}
\hline Building element & $\begin{array}{c}\text { Area } \\
{\left[\mathrm{m}^{2}\right]}\end{array}$ & $\begin{array}{c}\text { Transmittance }\left[\mathrm{W} \mathrm{m}^{-2} \mathrm{~K}^{-}\right. \\
]\end{array}$ \\
\hline External wall & 987.5 & 0.94 \\
External stairwell wall & 93.0 & 2.31 \\
External lift shaft wall & 281.8 & 3.22 \\
Internal stairwell wall & 627.6 & 2.50 \\
Floor towards cellars & 343.5 & 1.35 \\
Ceiling towards attic & 658.6 & 1.72 \\
Cellar ground floor & 348.9 & 0.55 \\
Stairwell ground floor & 90.8 & 0.67 \\
Attic and stairwell roof & 683.9 & 1.71 \\
Apartment security & 50.4 & 1.12 \\
doors & & \\
Attic windows & 9.6 & 4.57 \\
Cellar windows & 16.5 & 4.56 \\
Stairwell windows & 30.7 & 5.80 \\
Stairwell door windows & 21.2 & 4.46 \\
\hline
\end{tabular}

All thermal bridges concerning Hue heat transfer coefficient, both outwards and towards the ground, have been numerically calculated by THERM software, according to UNI EN ISO 10211 [9] and UNI EN ISO 10077-2 [10] standards.

Figure 2 shows the considered thermal bridges, highlighting their location in the building.

In particular, the horizontal thermal bridges on the perimeter of the rooms are to be considered both ceiling and floor. The dashed lines refer to horizontal thermal bridges concerning the horizontal heat fluxes towards the external environment (e) and vertical fluxes towards heated rooms (i) and ground (g); the solid lines refers to horizontal thermal bridges due to the adiabatic wall between unheated rooms, that involve only vertical fluxes towards heated rooms (i).

In order to evaluate linear transmittance of thermal bridges involving three temperatures (indoor temperature $\mathrm{Ti}$, outdoor temperature Te and unconditioned space temperature $\mathrm{Tu}$ ), the same hypotheses and the same THERM models already described in [4] and [11] have been used; in the present study both the contribution to Hiu and Hue of each thermal bridge are considered separately. 


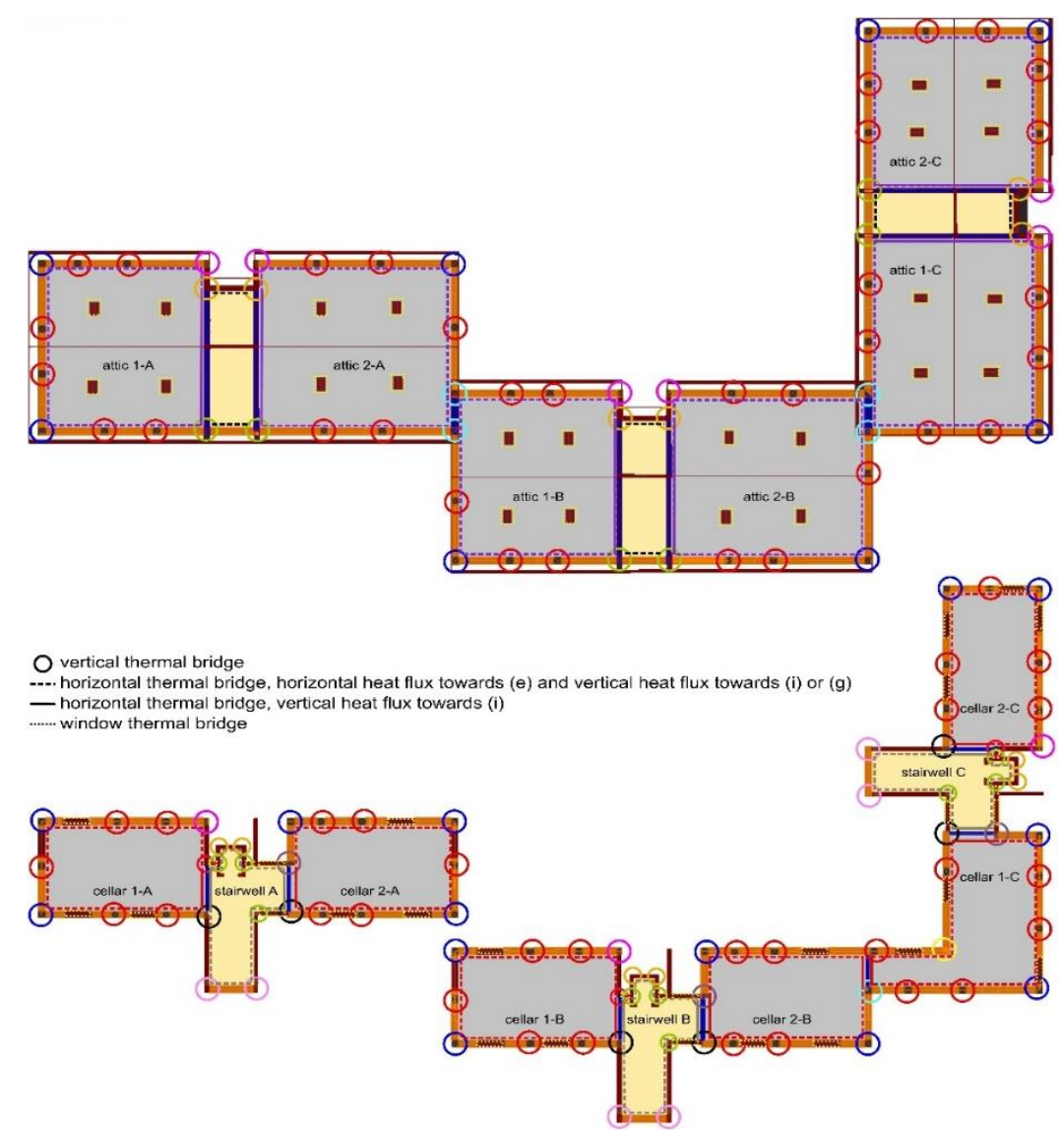

Figure 2. $\mathrm{H}_{\mathrm{ue}}$ and $\mathrm{H}_{\mathrm{iu}}$ thermal bridges for unconditioned spaces

The steady-state heat transfer between cellars and ground has been modeled using the method c) of the UNI EN ISO 13370 [12]:

$\mathrm{H}_{\mathrm{g}}=\mathrm{AU}+\mathrm{P} \psi_{\mathrm{wf}}$

$\mathrm{H}_{\mathrm{g}}=$ steady state heat transfer coefficient via the ground

$\mathrm{A}=$ floor area of the cellar

$\mathrm{U}=$ thermal transmittance between cellar and the ground

$\mathrm{P}=$ exposed perimeter

$\psi_{\mathrm{wf}}=$ linear thermal transmittance of the wall/floor junction

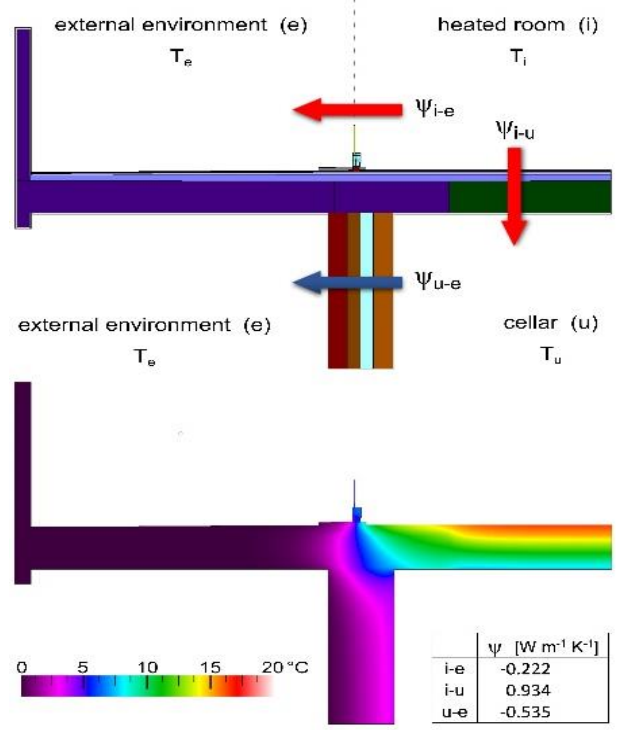

Figure 3. Three temperature thermal bridge THERM model
As an exemple, THERM models and calculated linear transmittances referred to external measures, concerning a three temperature and a ground thermal bridge are depicted respectively in Figure 3 and Figure 4. Temperatures of unconditioned spaces are assessed accordingly by formula (2) using the default value of $b_{t r, U}$ factor.

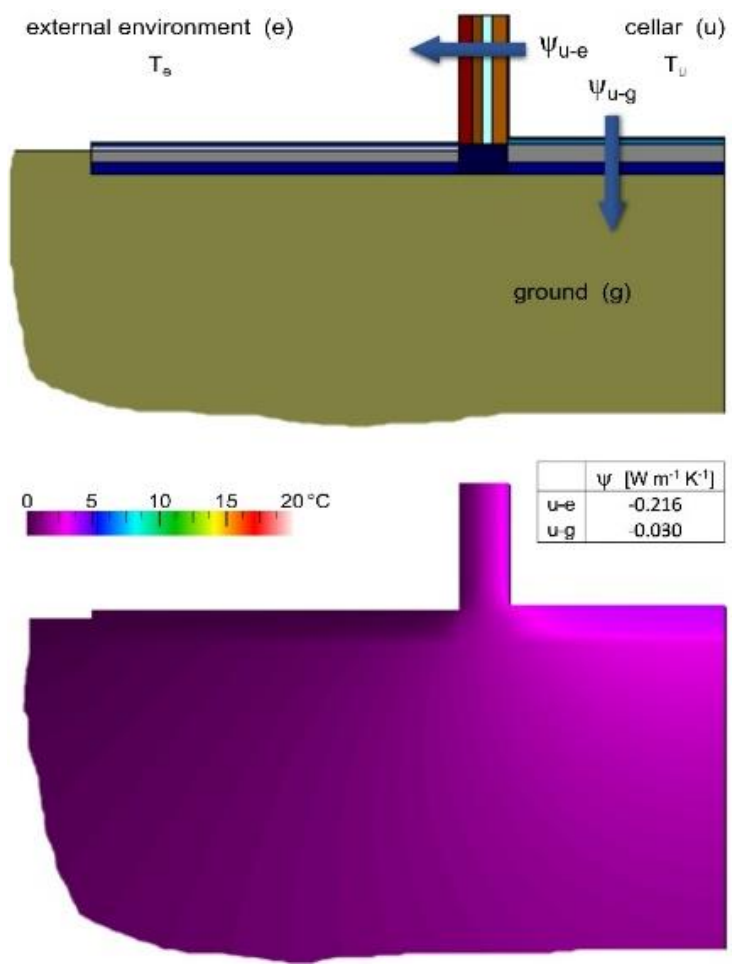

Figure 4. Via ground thermal bridge THERM model 


\section{RESULTS AND DISCUSSION}

The simulations are carried out by the commercial software EC700 of EDILCLIMA ${ }^{\circledR}$ software-house [13], in compliance with the UNI/TS 11300-1 standard, based on monthly calculation method.

Figure 5 shows the comparison on the $b_{t r, U}$ factor determined in the three above mentioned conditions for all the unconditioned spaces in the building: default values (solid line), analytical calculation (formula 3) without considering thermal bridges that compete with the $\mathrm{H}_{\mathrm{ue}}$ coefficient (blue), analytical calculation (formula 3 ) considering thermal bridges that compete with the $\mathrm{H}_{\mathrm{ue}}$ coefficient (orange).

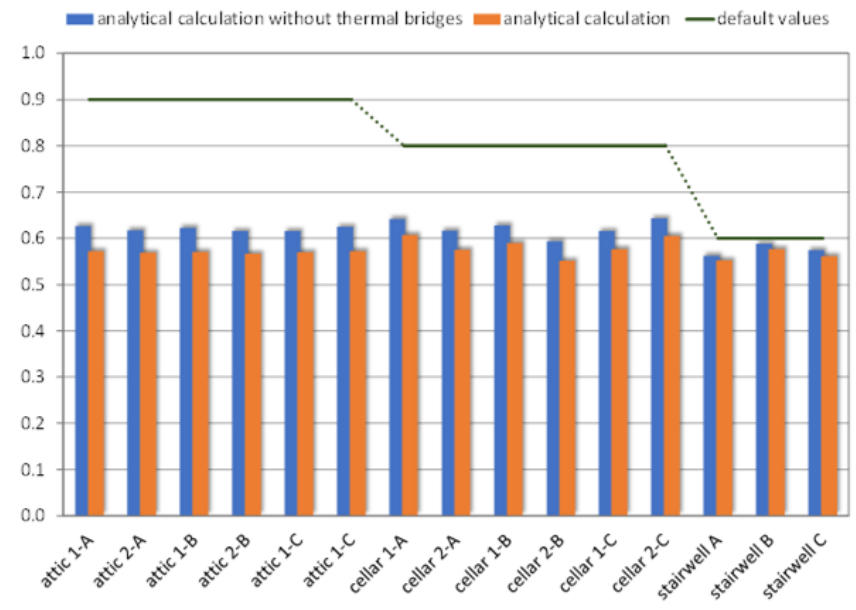

Figure 5. Comparison on $b_{t r, U}$ values of unconditioned spaces

It results that for the stairwells the default value of $b_{t r, U}$ deviates slightly from the analytical one, while there are greater deviations for the cellars and even more for the attics. In all cases, the default values lead to an overestimation of the heat exchange via unconditioned rooms.

For the stairwells, the contribution of thermal bridges relative to the $\mathrm{H}_{\mathrm{ue}}$ coefficient is negligible, while it is more significant for the attics and the cellars. Note that the $b_{t r, U}$ factor for attics and cellars is higher if the contribution of the thermal bridges is neglected: this is due to the fact that the thermal bridges have negative values of linear transmittances because the dimensional system, used in the present study, is based on the external dimensions [14].

Mean temperatures of three different types of unconditioned spaces $T_{u}$ are shown in Figure 6, for attics (Figure 6a), cellars (Figure 6b) and stairwells (Figure 6c).

Mean monthly outdoor temperatures $\mathrm{T}_{\mathrm{e}}$ provided by UNI 10349-1 [15] and indoor temperatures $T_{i}$ are also represented, considering an internal set point temperature of $20{ }^{\circ} \mathrm{C}$ in the months from October to April inclusive (heating season) and $26{ }^{\circ} \mathrm{C}$ in the other months (cooling season). If default values of $b_{t r, U}$ factor are considered, temperature $T_{u}$ is calculated by formula (2); in case of analytical calculations formula (7) is used.

The $\mathrm{T}_{\mathrm{u}}$ trend reflects what has already been observed about the $b_{t r, U}$ factor in Figure 5, that is there are significant differences between the analytical calculation and the default one for attics and cellars, while the two methods are aligned for stairwells.

Note that in summer conditions the temperatures $T_{u}$ determined by the analytical calculation are closer to the internal temperature $\mathrm{T}_{\mathrm{i}}$ than in winter conditions. This is due to the contribution of solar heat gains. To better understand this aspect see Figure 7. The graph shows the temperature $T_{u}$ of different unconditioned spaces in the case of analytical calculations in the presence and in the absence $(\Phi=0)$ of the contribution of the solar gains and the extra heat flux towards the sky; this last condition is equivalent to calculating $\mathrm{b}_{\mathrm{tr}, \mathrm{U}}$ by formula (3) and then $\mathrm{T}_{\mathrm{u}}$ by formula (2).
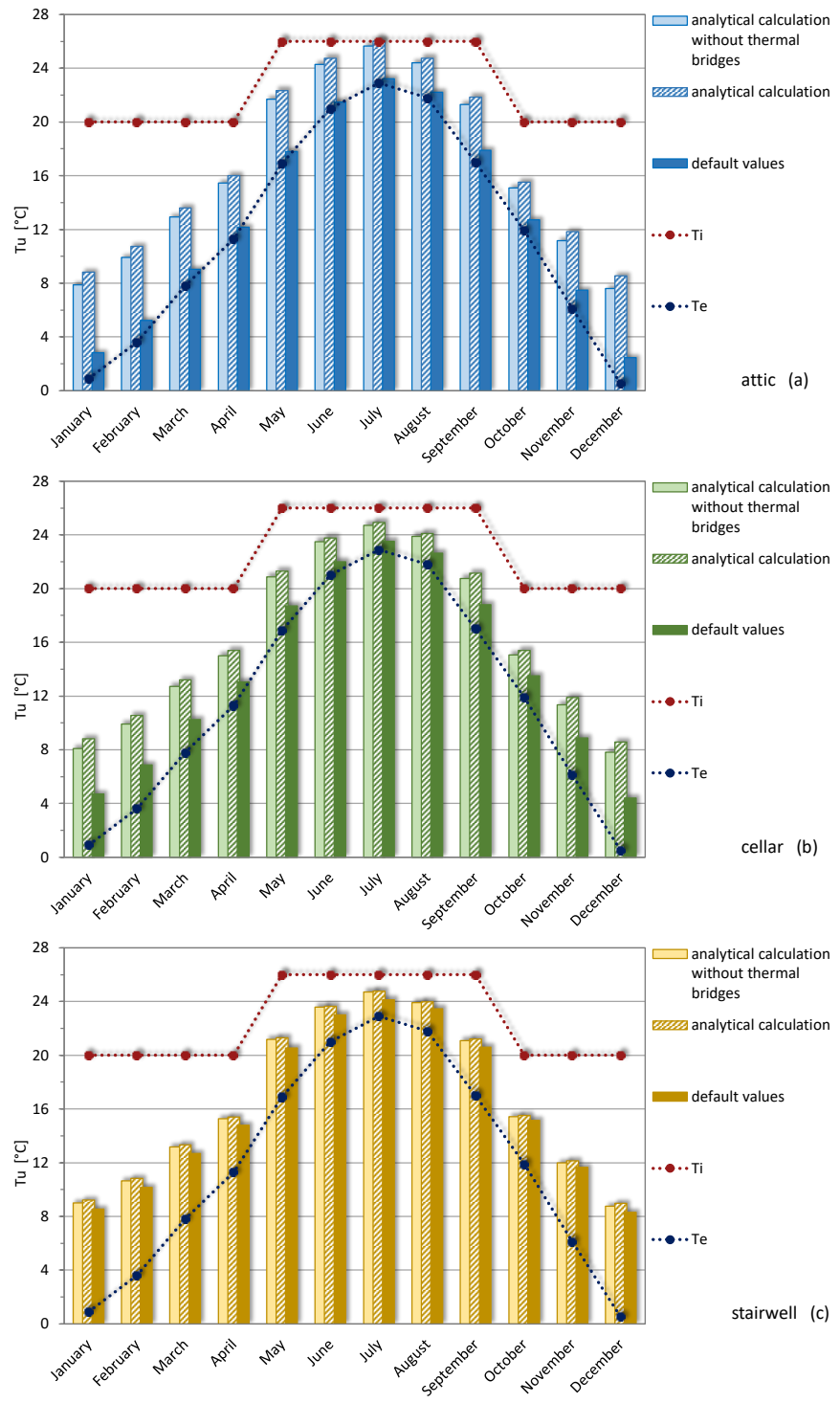

Figure 6. Comparison on $T_{u}$ values for attics (a), cellars (b) and stairwells (c)

Comparison of three methods is also carried out with reference to both the thermal energy needs of entire building and each housing unit.

Figure 8 shows the thermal energy need $\mathrm{Q}_{\mathrm{H}, \mathrm{nd}}$ of the entire building: default calculation leads to overestimate the building need by over $6 \%$ respect to analytical calculation; the error on $\mathrm{Q}_{\mathrm{H}, \mathrm{nd}}$, not considering the thermal bridges in the calculation of $\mathrm{H}_{\text {ue }}$, is equal to $1 \%$.

Finally, Figure 9 shows the comparison of three procedures on condominium millesimal table.

Results are particularly significant for the application of the Italian UNI 10200 [6] standard concerning the subdivision of expenses in condominiums equipped with centralized heating systems and with thermal control and heat metering devices.

In fact, this rule provides that the costs related to both the involuntary consumption due to plant generation and 
distribution energy losses and to the plant management and maintenance are divided on the basis of millesimal tables based on the energy needs $\mathrm{Q}_{\mathrm{H}, \mathrm{nd}}$ of single housing units. Different calculation methods of the heat transfer via unconditioned spaces can lead to a different distribution of costs. It is important to distinguish between the apartments located on the first and the last floors and those located on the intermediate floors.
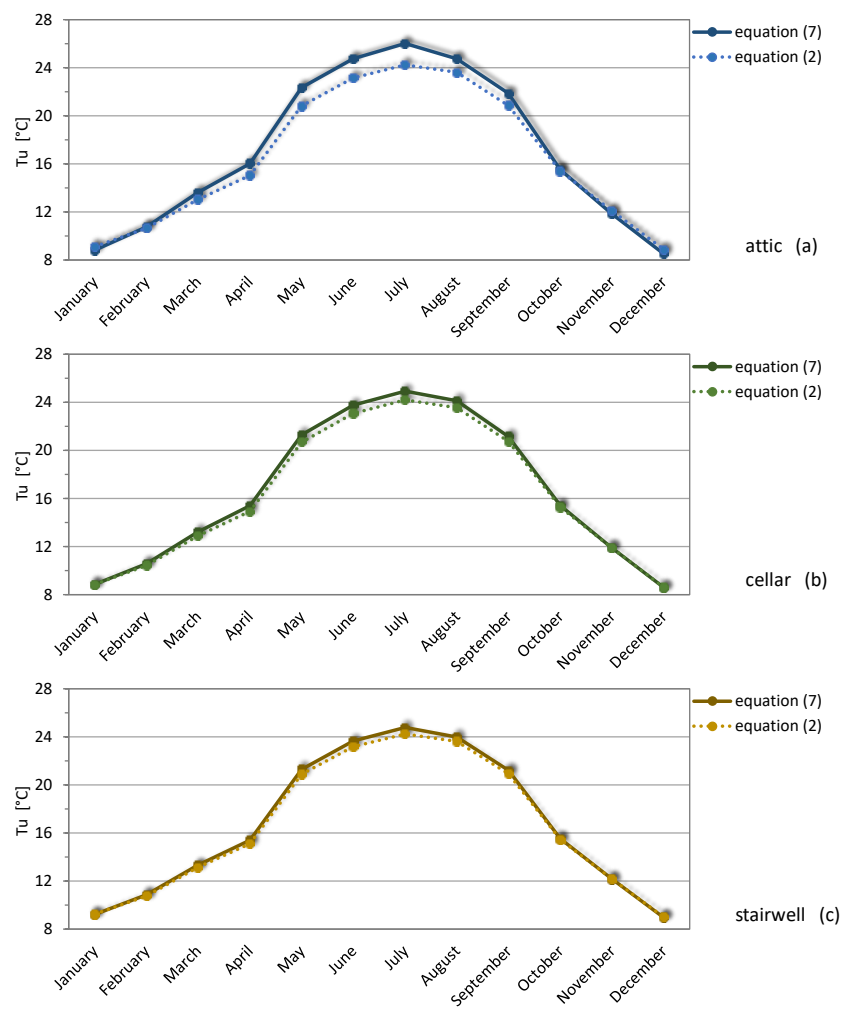

Figure 7. Effect of heat flux $\Phi$ on mean temperature of unconditioned spaces: attics (a), cellars (b) and stairwell (c)

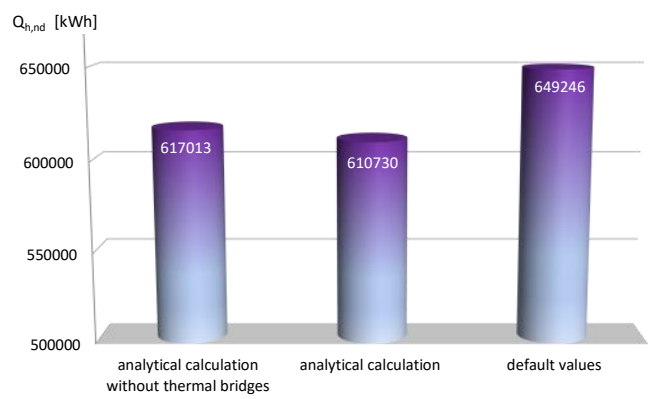

Figure 8. Comparison on $\mathrm{Q}_{\mathrm{H}, \mathrm{nd}}$ values of entire building

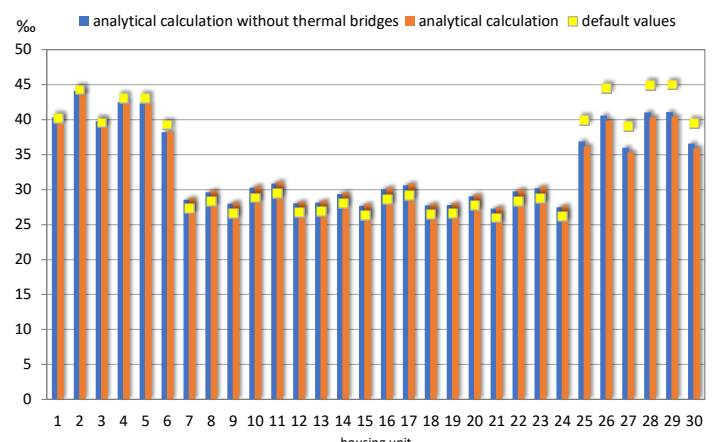
housing unit

Figure 9. Comparison on condominium millesimal table
It results that the overestimation of the thermal exchanges, obtained by the default calculation procedure for attics and cellars, significantly penalizes the apartments on the top floor and, although to a lesser extent, those on the ground floor; the apartments on the intermediate floors have instead benefited. The thousandths of heating calculated with the default method can exceed even $10 \%$ those calculated with the analytical method in the case of top floor apartments.

\section{CONCLUSIONS}

Three different calculation procedures for the heat transfer via unconditioned spaces in energy performance of buildings have been compared. The following conclusions can be drawn.

(1). default values of $b_{t r, U}$ lead to an overestimation of the heat exchange via unconditioned rooms respect to analytical calculation, in particular for attics and cellars;

(2). default calculation leads to overestimate the building energy need $\mathrm{Q}_{\mathrm{H}, \mathrm{nd}}$ by over 6\% respect to analytical calculation;

(3). the contribution of thermal bridges in $\mathrm{H}_{\mathrm{ue}}$ coefficient is negligible; it follows that a future revision of the standard could make it possible to disregard the contribution of thermal bridges between unconditioned spaces and external environment and ground;

(4). different calculation procedures for heat transfer via unconditioned spaces can significantly influence the millesimal tables of heating in buildings equipped with centralized systems and thermal control and heat metering devices.

\section{ACKNOWLEDGMENT}

This research was funded by the University of Genoa research project PRA2017.

\section{REFERENCES}

[1] Energy Performance of Buildings. (2014). Part 1. Evaluation of Energy Need for Space Heating and Cooling, UNI/TS 11300-11301.

[2] Energy Performance of Buildings. (2008). Calculation of Energy Use for Space Heating, UNI EN ISO 13790.

[3] Energy Performance of Buildings. (2018). Energy Needs for Heating and Cooling: Internal Temperatures and Sensible and Latent Heat Loads, UNI EN ISO 52016-1.

[4] Bergero S, Chiari A. (2018). The influence of thermal bridge calculation method on the building energy need: a case study. Energy Procedia 148: 1042-1049. https://doi.org/10.1016/j.egypro.2018.08.056

[5] Lawrence Berkeley National Laboratory. THERM Finite Element Simulator (version 7.6.1), https://windows.lbl.gov/software/therm/therm.html

[6] Centralized Heating System for Space Heating, Cooling and Domestic Hot Water Production: Heating, Cooling and Domestic Hot Water Costs, UNI 10200, 2018.

[7] Energy Performance of Buildings. (2018). Method for Calculation of the Design Heat Load, Part 1: Space Heating Load, Module M3-3, UNI EN 12831-12831.

[8] Thermal Performance of Buildings. (2018). Transmission and Ventilation Heat Transfer Coefficients. Calculation Method, UNI EN ISO 13789. 
[9] Thermal Bridges in Building Construction. (2018). Heat Flows and Surface Temperatures. Detailed Calculations, UNI EN ISO 10211.

[10] Thermal Performance of Windows, Doors and Shutters. Calculation of Thermal Transmittance, Part 2: Numerical Method for Frames, UNI EN ISO 10077-2, 2018.

[11] Bergero S, Cavalletti P, Chiari A. (2017). Energy refurbishment in existing buildings: Thermal bridge correction according to DM 26/06/2015 limit values. Energy Procedia 140: 127-140. https://doi.org/10.1016/j.egypro.2017.11.129

[12] Thermal Performance of Buildings. (2018). Heat Transfer via the Ground. Calculation Methods, UNI EN ISO 13370.

[13] EDILCLIMA® Engineering \& Software, EC 700 (version 9.19), https://www.edilclima.it

[14] Thermal Bridges in Building Construction. (2018). Linear Thermal Transmittance. Simplified Methods and Default Values, UNI EN ISO 14683.

[15] Heating and Cooling of Buildings. (2016). Climatic Data, Part 1: Monthly Means for Evaluation of Energy Need for Space Heating and Cooling and Methods for Splitting Global Solar Irradiance into the Direct and Diffuse Parts and for Calculate the Solar Irradiance on Tilted Planes, UNI 10349-1.

\section{NOMENCLATURE}

$\begin{array}{ll}\mathrm{A} & \text { area, } \mathrm{m}^{2} \\ \mathrm{~b} & \text { adjustment factor }\end{array}$

\section{Greek symbols}

$\Phi$

$\psi$

\section{Subscripts}

e

$\mathrm{g}$

$\mathrm{H}$

i

nd

$\operatorname{tr}$

$\mathrm{U}, \mathrm{u}$

ve

w specific heat, $\mathrm{J}^{\mathrm{kg}}{ }^{-1} \cdot \mathrm{K}^{-1}$

heat transfer coefficient, W. $\mathrm{K}^{-1}$ length, $\mathrm{m}$ air renewal rate, $\mathrm{h}^{-1}$ perimeter, $\mathrm{m}$ thermal energy, $\mathrm{J}$ temperature, $\mathrm{K}$ transmittance, $\mathrm{W} \cdot \mathrm{m}^{-2} \cdot \mathrm{K}^{-1}$ volume, $\mathrm{m}^{3}$

density, $\mathrm{kg} \cdot \mathrm{m}^{-3}$

heat flux, $\mathrm{W}$

linear transmittance, $\mathrm{W} \cdot \mathrm{m}^{-1} \cdot \mathrm{K}^{-1}$

external

floor

ground

heating

internal

needed

transmission unconditioned ventilation

wall 